\title{
Circularly Polarized Slot Antenna Array with Sequentially Rotated Feed Network for Broadband Application
}

\author{
Saeid Karamzadeh, ${ }^{1,2}$ Bal. S. Virdee, ${ }^{3}$ Vahid Rafii, ${ }^{4}$ Mesut Kartal $^{2}$ \\ ${ }^{1}$ Department of Electric and Electronics Engineering, Istanbul Aydin University, Istanbul, Turkey \\ ${ }^{2}$ Department of Electric and Electronics Engineering, Istanbul Technical University, Istanbul, Turkey \\ ${ }^{3}$ London Metropolitan University, Center for Communications Technology, Faculty of Life Sciences \\ and Computing, London, United Kingdom \\ ${ }^{4}$ Young Researchers and Elite Club, Urmia Branch, Islamic Azad University, Urmia, Iran
}

Received 28 April 2014; accepted 15 October 2014

\begin{abstract}
This article presents a novel circularly polarized sequentially rotated slot antenna array (CPSSAA) designed to operate at a frequency of $5.5 \mathrm{GHz}$. This antenna is suitable for communication applications such as WLAN/WiMAX. Method of feeding is based on sequential rotation with seven quarter-wavelength transformers. In this case, the elements with $200 \Omega$ impedance could be replaced by other elements with different input impedance. Reducing the elements input impedance, maximum power can be transferred to the elements. Because the lower losses in transmission line occur in presence of lower impedance, the $3 \mathrm{~dB}$ axial-ratio bandwidth of the CPSSAA extends to $\sim 1.3 \mathrm{GHz}$. The CPSSAA was designed to operate over the frequency range between 4.5 and $6.4 \mathrm{GHz}$ corresponding to an impedance bandwidth of $34.86 \%$ for $V S W R<2$. Acceptable agreement between the simulation and measured results validates the proposed design. (c) 2014 Wiley Periodicals, Inc. Int J RF and Microwave CAE 25:358-363, 2015.
\end{abstract}

Keywords: planar antenna; slot antenna; array antenna; circularly polarized; feed network

\section{INTRODUCTION}

The use of circularly polarized (CP) antennas have advantages such as: very effective in combating multipath interferences or fading, able to reduce the "Faraday rotation" effect due to the ionosphere and no strict orientation between transmitting and receiving antennas are required [1-23]. The inherent narrow axial-ratio (AR) bandwidth of the conventional patch antenna leads to limit their applications. The printed CP slot antennas attract much attention due to their capabilities of providing wide impedance and AR bandwidths while maintaining the low profile. Coplanar Waveguide (CPW) and microstrip line feeds are the most preferred feeding structures for the slot antenna design. Hitherto, several feed techniques are introduced for achieving CP property in microstrip arrays, for instance: (I) series

Correspondence to: S. Karamzadeh; e-mail: karamzadeh@itu.edu.tr DOI: 10.1002/mmce. 20869

Published online 6 November 2014 in Wiley Online Library (wileyonlinelibrary.com). feed [3], (II) parallel feed [4], and (III) sequentially rotation feed [5]. Methods I and II are traditional and have some drawbacks in realization of this types of arrays, which can be noted: increment effective length of array and hard to realize in method I, unbalanced pattern and mutual coupling effect between elements and feed network in method II. Many researches have been suggested the coplanar corporate-fed arrays that consist of sequentially rotated $\mathrm{CP}$ elements [1, 5, 19, 22, 23] and a significant improvement has been achieved in the AR bandwidth. However, such feeding structures for microstrip patch arrays leads to performance deteriorations due to feed radiation [10]. Then, to overcome this problem, coplanar serial-fed antenna arrays have been reported in [13-21]. The serial feed sequentially rotated element technique improves the bandwidth, radiation pattern, and polarization purity over a wider frequency band compared to the classical coplanar corporate feed network, but thin substrate is recommended at the cost of narrow bandwidth [17]. Besides additionally, 3-dB AR bandwidth of the antenna arrays is no more than $20 \%$. One of the ways that leads to greater gain and $\mathrm{CP}$ bandwidth in

(C) 2014 Wiley Periodicals, Inc. 


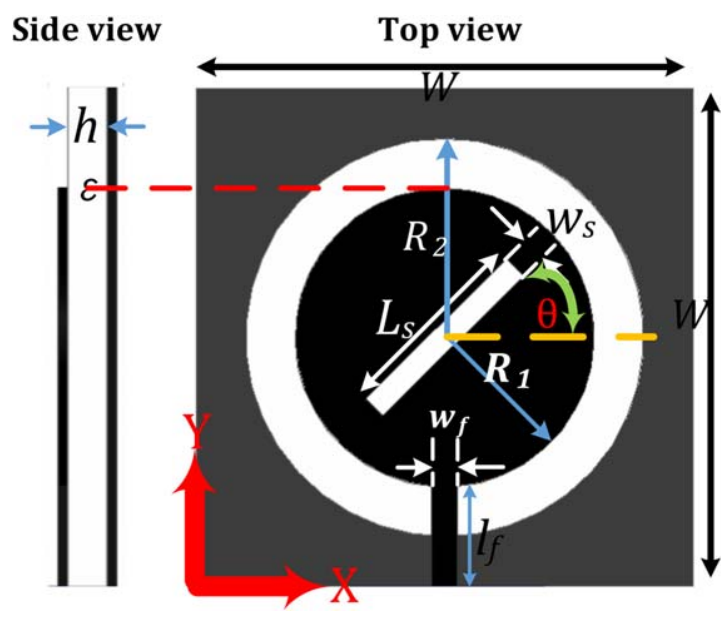

Figure 1 Geometry of the proposed CP slot antenna.

antenna array will be used the $\mathrm{CP}$ element. The antennas composed of linearly polarized elements leads to a gain reduction exceeding $4 \mathrm{~dB}$ compared with that for $\mathrm{CP}$ elements when the element spacing exceeds 0.75 of free-space wavelength [1, 2].

The most important characteristic of this antenna is to use an element with input impedance of $50 \Omega$. Generally, an element with $200 \Omega$ input impedance element was used and to match with $50 \Omega$ input impedance, two $200 \Omega$ impedances were placed. Conversely low input impedance value of radiated element causes an increase in power into the element and increase in gain too. The other important characteristic of this antenna is the usage of gapped ground at the bottom of the element, which causes yields an increase in the bandwidth of the whole array. The general opposite relationship between gain and bandwidth stands here too [16]. However, in this article the proposed method which has used an element with low impedance, results in adjustment in gain of the Antenna. A broadband $\mathrm{CP}$ array antenna composed of the $\mathrm{CP}$ elements fed by the microstrip lines is presented. A detail of the antenna configuration, simulation, and practical results for the proposed array antenna are discussed. This article is organized as follows. Section II describes the design and configuration of the broadband CP antenna element. Section III explains the design of the broadband CP $2 \times 2$ antenna array. Both measured and simulated results are presented and discussed. Section IV gives the conclusions.

\section{SINGLE ELEMENT DESIGN}

The geometry and dimensions of the proposed CP slot antenna element is shown in Figure 1. The antenna array

TABLE I The Optimized Geometrical Parameters of the Antenna Element

\begin{tabular}{lclc}
\hline Parameter & Value $(\mathrm{mm})$ & Parameter & Value $(\mathrm{mm})$ \\
\hline$W$ & 30 & $W_{s}, W_{f}$ & 1.5 \\
$R_{1}$ & 9 & $L_{\mathrm{f}}$ & 6 \\
$R_{2}, L_{s}$ & 12 & $h$ & 0.8 \\
\hline
\end{tabular}

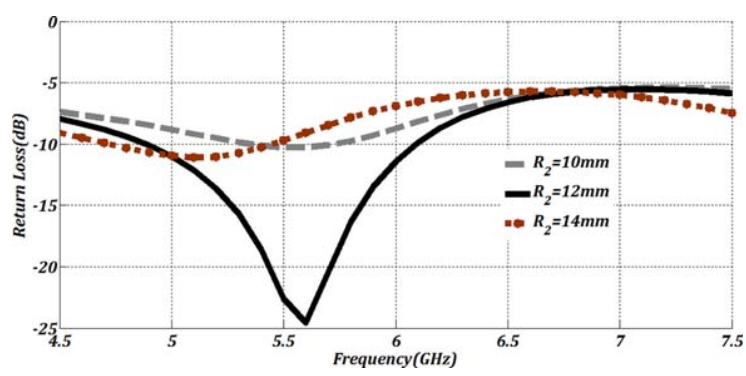

Figure 2 The $S_{11}$ curve for various patch slot length $R_{2}$ as a function of frequency.

element has been designed on FR4 dielectric substrate with relative permittivity $\varepsilon_{\mathrm{r}}=4.4$, and loss tangent $(\tan \delta)=0.02$. To The dimensions of element are $30 \times 30$ $\times 0.8 \mathrm{~mm}^{3}$, where the parameters defining, the structure (units in $\mathrm{mm}$ ) is given in Table I.

The antenna array element is consist of a circular slot with a radius $R_{2}$ is etched on the ground plane with an area of $W \times W$ and a rectangular slot is notched on the circular disk with a radius $R_{1}$. All parameters of the proposed single element antenna has designed and optimized by High Frequency Structure Simulator (Ansoft HFSS v.13). To achieve the $50 \Omega$ microstrip fed line is used of $W_{\mathrm{f}}=1.5 \mathrm{~mm}$. To attain a deeper insight of how the antenna's parameters influence its performance a parametric study was necessary. Figure 2 shows the effect of the length parameter $R_{2}$ on the antenna's $S_{11}$ response. As shown in Figure $2, R_{2}$ mainly affects the impedance frequency bandwidth. This is the key parameter that enables the desired WLAN Band $(5-6 \mathrm{GHz})$ for which $R_{2}=12 \mathrm{~mm}$.

Furthermore Figure 3 shows the simulated $3 \mathrm{~dB}$ AR characteristics of the antenna as a function of angle $\theta$. When $\theta$ is changed from $15^{\circ}$ to $30^{\circ}$, the $3 \mathrm{~dB}$ AR bandwidth at maximum direct of gain increasing from $0 \%$ to at around $9 \%$. Therefore, through this analysis $\theta$ was fixed at $30^{\circ}$.

This distribution on the disk is changed by the rectangular slot. The rectangular slot alters the current distribution on the disk to excite the circular slot to generate $\mathrm{LHCP}$ radiation in $+\mathrm{z}$ direction (Fig. 4). The AR bandwidth of the antenna can be improved by tuning the size $\left(L_{\mathrm{s}}\right.$ and $\left.w_{\mathrm{s}}\right)$ and angle $(\theta)$ of the rectangular slot. The resonant frequency is mainly determined by the size of the circular disk and circular slot. A parametric study is

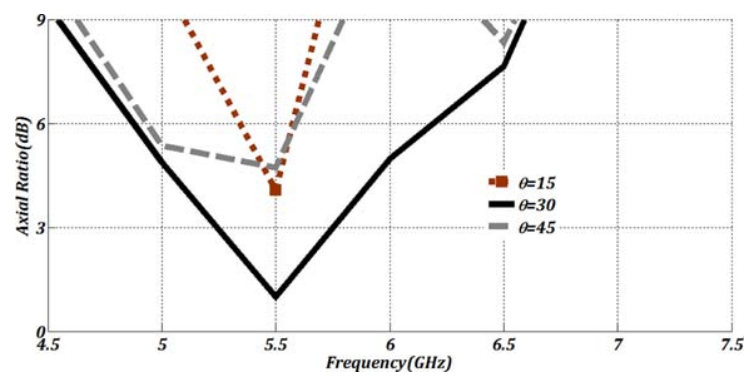

Figure 3 Simulated AR for changing angle $\theta$. 


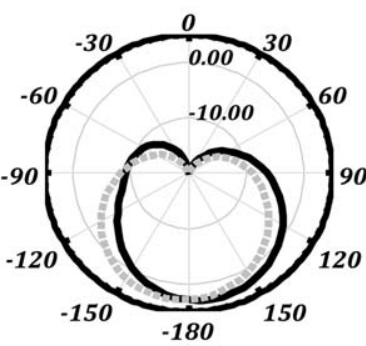

(a)

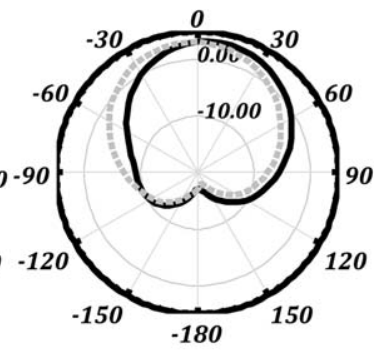

(b)
Figure 4 The simulated pattern of single element antenna (a) RHCP (b) LHCP at $5.5 \mathrm{GHz}$.

undertaken to evaluate the effects of the antenna dimensions on the return loss and AR. The proposed CP Antenna has an area of $900 \mathrm{~mm}^{2}\left(30 \times 30 \mathrm{~mm}^{2}\right)$, which is considerably less than the previously published slot antennas as summarized in Table II along with other salient parameters. Compared with other similar types of CP slot antennas fabricated on the same substrate the proposed antenna exhibits an impedance bandwidth which is significantly larger and with no reduction in the gain performance, as well as having a larger circular polarization bandwidth. The gain is comparable to previous designs.

\section{FEED NETWORK DESIGN}

Effects of the sequentially rotated technique in constructing antenna array have been reported in many articles [1, $5,22,23]$. A $2 \times 2$ sequentially rotated array is designed by using the proposed broadband $\mathrm{CP}$ slot antenna. The proposed $\mathrm{CP}$ feed network consists of seven quarterwavelength transformers that are linked together in a sequential rotation manner with alternative parallel and series connections to form a four port network. Ports 1-4 are output ports, which are connected to respective microstrip patch elements with their impedance $Z=50 \Omega$ (as shown in Fig. 1). Consequently, all four patch elements are positioned symmetrically and can generate a circular polarization with good ARs. Seven quarter-wave transformers were designed in a circular shape, to reduce the discontinuity.

All the line sections are a quarter-wavelength in length, but with different characteristic impedances. The network then produces a phase shift of $90^{\circ}$ and equal power split between adjacent output ports. In other words, the signal amplitudes at the four ports that are fed to each

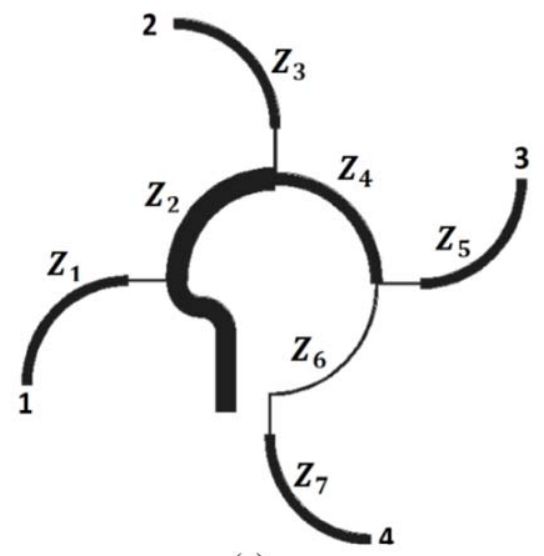

(a)

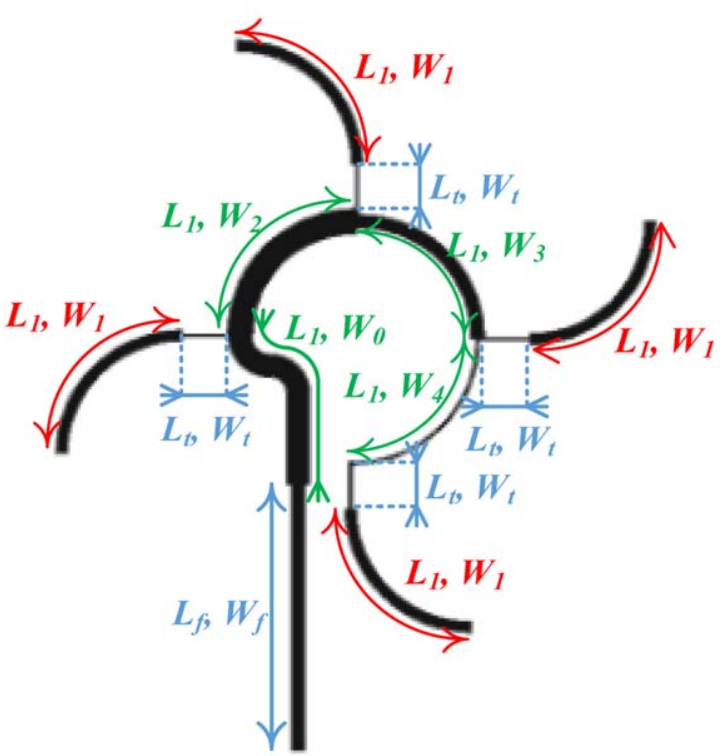

(b)

Figure 5 (a) Feed network of the CPSSAA. (b) Configuration of the feed network of the proposed CPSSAA.

patch element are theoretically identical, but with a $90^{\circ}$ phase difference among two adjacent ports. The required input impedance to the overall feed network or the main input feed line is $Z_{0}=50 \Omega$ (Fig. 5). The configuration of the array network was designed and simulated by using Agilent $^{\mathrm{TM}}$ Advance Design System commercial software.

TABLE II Comparison of the Proposed CPSSA Antenna Size and Measured Characteristics with Other References

\begin{tabular}{lcrcr} 
Ref. & Size $\left(\mathrm{mm}^{3}\right)$ & \multicolumn{1}{c}{ BW $(\mathrm{GHz})$} & $3 \mathrm{~dB}$ ARBW $(\mathrm{GHz})$ & Peak Gain (dBic) \\
\hline$[17]$ & $70 \times 70 \times 1.60$ & $0.85(1.75-2.6)$ & $0.4(1.7-2.1)$ & 3.7 \\
{$[18]$} & $70 \times 70 \times 1.60$ & $0.20(1.5-1.7)$ & $0.3(1.5-1.8)$ & 3.5 \\
{$[19]$} & $70 \times 70 \times 1.60$ & $0.80(1.6-2.4)$ & $0.2(1.8-2.0)$ & 3.5 \\
{$[20]$} & $60 \times 60 \times 0.76$ & $0.80(1.7-2.5)$ & $0.7(1.8-2.5)$ & 3.5 \\
{$[21]$} & $60 \times 60 \times 0.74$ & $1.40(1.6-3.0)$ & $0.7(2.3-3.0)$ & 4.0 \\
This work & $30 \times 30 \times 0.80$ & $1.2(4.9-6.1)$ & $0.5(5.25-5.75)$ & 3.7
\end{tabular}

Dielectric substrate used is FR4 with $\varepsilon_{\mathrm{r}}=4.4, \tan \delta=0.024$. The impedance bandwidth is for a frequency range where the VSWR $\leq 2$; and ARBW is the 3-dB AR bandwidth. 


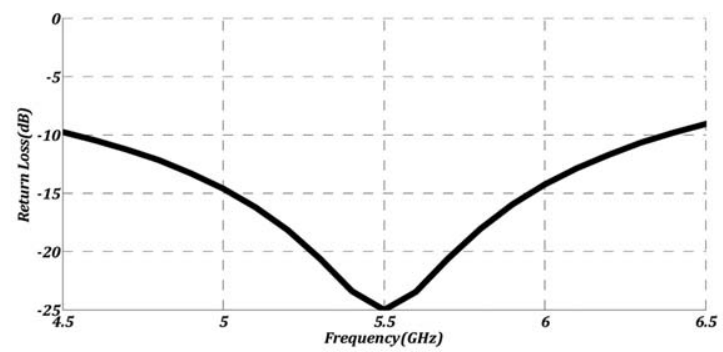

(a)

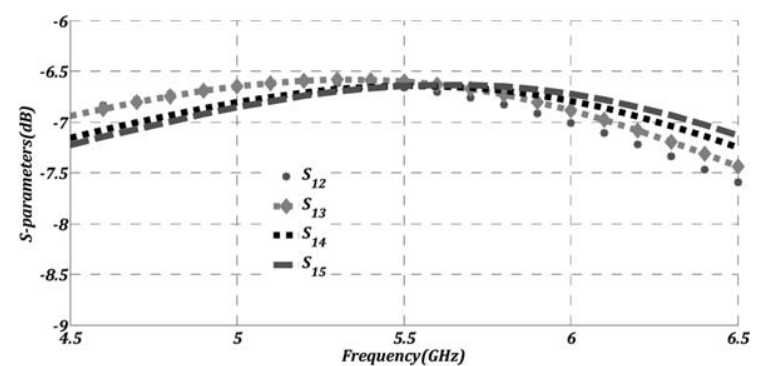

(b)

Figure 6 (a) The simulated $S_{11}$ values of the feed network and (b) The simulated $S_{12}, S_{13}, S_{14}$, and $S_{15}$ values of the feed network.

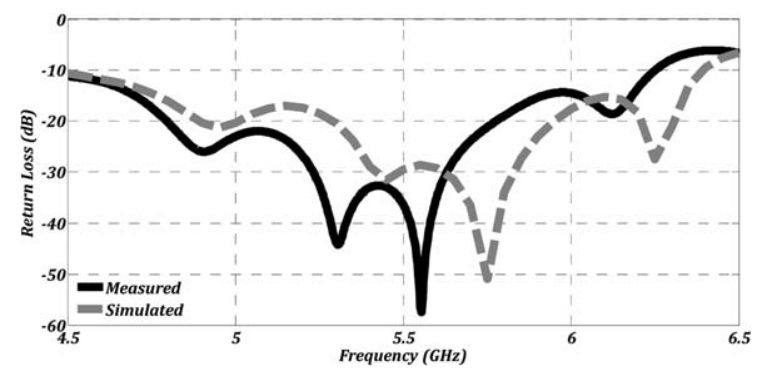

Figure 7 The differences between the simulation and measurement results of return loss.

The simulated $S$, as a function of frequency is presented in Figure 6a.

The impedance bandwidth of this feeding network, defined as the frequency with an $S_{11}$ above $10 \mathrm{~dB}$, covered the frequency band from 4.56 to $6.41 \mathrm{GHz}$. Figure $6 \mathrm{~b}$ plots the $S$ parameters of the five port feed network. According to this figure, all ports were matched, and the transmission coefficient was $6.6 \mathrm{~dB}$ from the input port to

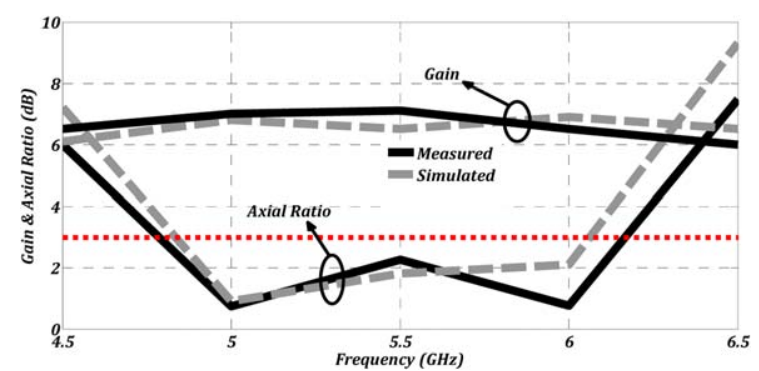

Figure 8 The differences between the simulation and measurement results of AR and gain of proposed CPSSAA.

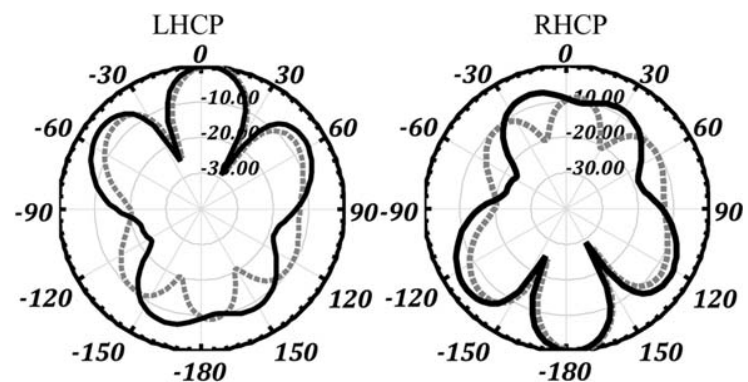

(a)

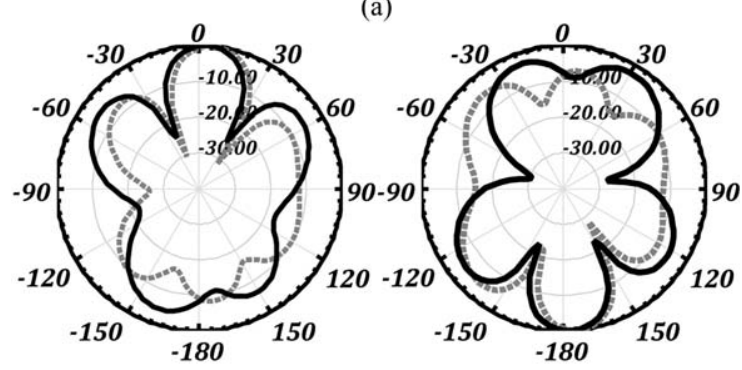

(b)

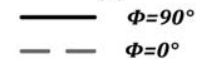

Figure 9 The normalized (a) measured and (b) simulated radiation patterns, at $\varphi=0^{\circ}$ and $\varphi=90^{\circ}$ at $5.5 \mathrm{GHz}$.

each output port. Length $(L)$ and width $(W)$ of each intersection transmission line lettered in Figure $2 \mathrm{~b}$ are as follows: $L_{1}=20 \mathrm{~mm}, L_{\mathrm{f}}=30 \mathrm{~mm}, L_{\mathrm{t}}=5 \mathrm{~mm}$, $W_{0}=2.6 \mathrm{~mm}, W_{1}=1.3 \mathrm{~mm}, W_{2}=2.8 \mathrm{~mm}, W_{3}=1.5 \mathrm{~mm}$, $W_{4}=0.3 \mathrm{~mm}, W_{\mathrm{f}}=1.5 \mathrm{~mm}$, and $W_{\mathrm{t}}=0.3 \mathrm{~mm}$.

\section{EXPERIMENTAL RESULTS AND DISCUSSION}

The proposed configuration of circularly polarized sequentially rotated slot antenna array (CPSSAA) is shown in Figure 3. The array antenna consists of four elements $(2$ $\times 2$ ) with 0.75 free space wavelength distances. The $S_{11}$

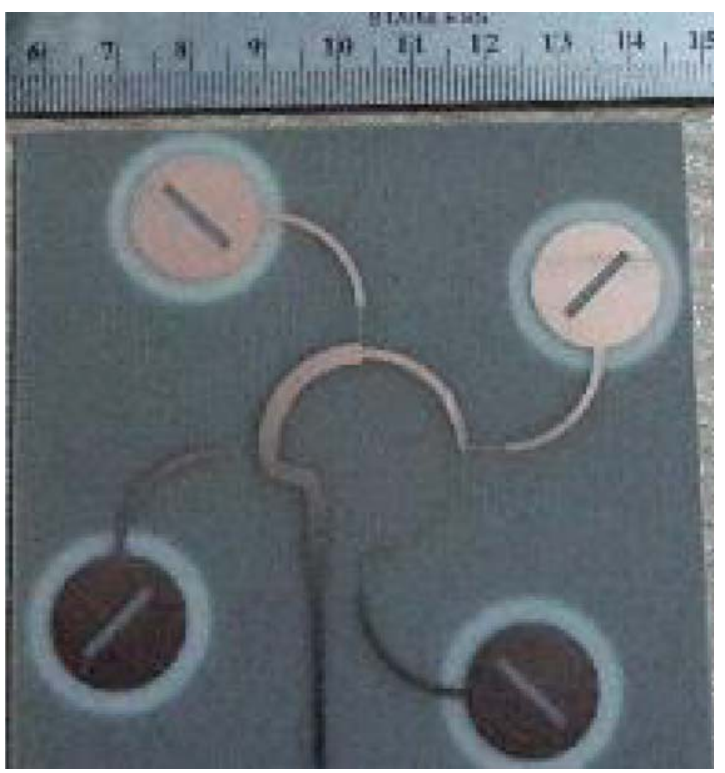

Figure 10 Photograph of the fabricated antenna. 
TABLE III Comparison of The Proposed Feed Network Structure and Measured Charactersistics with Other Array Antennas

\begin{tabular}{llcccc}
\hline Ref. & \multicolumn{1}{c}{ Feed Network } & BW (freq. range; GHz) & ARBW (freq. range; GHz) & PG (dBic) & Substrate \\
\hline$[22]$ & Asymmetric CPW & $0.80(1.1-1.9)$ & $0.80(1.1-1.9)$ & $\sim 7.5$ & $\sim 15$ \\
{$[23]$} & Aperture Coupled & $0.80(1.6-2.4)$ & $0.60(1.7-2.3)$ & RT/Duroid 5880 \\
This work & Symmetric Microstrip Slot & $1.7(4.5-6.2)$ & $1.47(4.75-6.22)$ & 7.2 & FR4 \\
\hline
\end{tabular}

The impedance BW is the frequency range where the VSWR $\leq 2$; and ARBW is the 3-db AR bandwidth.

and AR of the proposed antenna array were measured, and the $S_{11}$ was measured using the Agilent $^{\mathrm{TM}} 8722 \mathrm{ES}$ network analyzer. The measurements of the fabricated array were made and compared with the simulations. Figure 7 shows the input reflection coefficient of the array versus frequency. The measured results corroborate well with the simulated results. As can be seen, the simulated bandwidth is $1.9 \mathrm{GHz}$, or $34.86 \%$, from 4.5 to $6.4 \mathrm{GHz}$, while the measured $10-\mathrm{dB}$ impedance bandwidth is $1.7 \mathrm{GHz}$, or $31.77 \%$, from 4.5 to $6.2 \mathrm{GHz}$.

The differences between the simulation and measurement results could be attributed to practical factors such as fabrication imperfectness, material parameters errors, and measurement errors. However, both simulated and measured bandwidths are much larger than that of the single patch element that is $0.77 \mathrm{GHz}$ (from 4.95 to $5.72 \mathrm{GHz}$ ).

Figure 8 shows the measured and simulated results of AR of polarization and gain of the array. It can be seen that the simulation shows a $3 \mathrm{~dB}$ AR bandwidth of $1.29 \mathrm{GHz}$ from 4.8 to $6.09 \mathrm{GHz}$. The measurement shows a much wider 3-dB bandwidth from 4.75 to over $6.22 \mathrm{GHz}$. Besides, the AR bandwidth is much larger than that of the single patch antenna, which is $0.52 \mathrm{GHz}$ (from $5.2 \mathrm{GHz}$ to $5.72 \mathrm{GHz}$ ).

A standard linearly polarized waveguide BJ320 was used to measure the total gain characteristics. The measured peak gain at $5.5 \mathrm{GHz}$ is $7.2 \mathrm{dBic}$. The measured and simulated of normalized SSAA radiation patterns (LHCP at $+z$ direction and RHCP at $-z$ direction) at $\varphi=0^{\circ}$ and $\varphi=90^{\circ}$ is shown in Figures $9 \mathrm{a}$ and $9 \mathrm{~b}$. The first reason of side lobe in this antenna is the elements distance from each other (free-space wavelength of 0.75) that increase the zeros of array factor. The second reason is related to substrate. It is well known that when using FR4, high tangent losses would be inevitable. Photograph of the fabricated antenna is indicated in Figure 10. However, an appropriate gain was achieved in this study for the proposed structure. The design when compared with the previous $\mathrm{CP}$ array structures with sequential feed network and arc feed-line presented in Table III show significantly increased impedance bandwidth and AR bandwidth, that is, the impedance and $\mathrm{AR}$ bandwidth are, respectively, more than three and two fold wider than the previous designs.

\section{v. CONCLUSION}

This article presents CPSSAA with seven quarterwavelength transformers. Four quarter wavelength usage for matching impedance between $50 \Omega$ in element input impedance and array feed network. In this study by decreasing input impedance, an increase in current transmission, an increase in power, occurred. Antenna array consist of four elements $(2 \times 2)$ which each element have circular polarization. The measured results show the impedance bandwidth as $1.7 \mathrm{GHz}$, or $31.77 \%$, from 4.5 to $6.2 \mathrm{GHz}$. For $\mathrm{VSWR}<2$, and $\mathrm{AR}<3 \mathrm{~dB}$ is 4.75 to over $6.22 \mathrm{GHz}$.

\section{REFERENCES}

1. V. Rafii, J. Nourinia, C. Ghobadi, J. Pourahmadazar, and B.S. Virdee, Broadband circularly polarized slot antenna array using sequentially rotated technique for C-band applications, Antennas Wireless Propag Lett IEEE 12 (2013), 128-131.

2. S. Karamzadeh, V. Rafii, M. Kartal, O.N. Ucan, and B.S. Virdee, Circularly polarised array antenna with cascade feed network for broadband application in C-band, Electron Lett 50 (2014), 1184-1186.

3. K. Sood, R. Jyoti, and S.B. Sharma, Linear array modules with prescribed using waveguide shunt slot-fed Microstrip patch elements, Int J Microwave Wireless Technol 5(2013), 637-644.

4. J. Huang, A parallel-series-fed microstrip array with high efficiency and low cross polarization. Microwave Opt Technol Lett 5 (2007), 230-233.

5. J. Pourahmadazar, and V. Rafii, Broadband circularly polarised slot antenna array for L- and S-band applications, Electron Lett 48 (2012), 542-543.

6. K.L. Wong, and T.W. Chiou, Broad-band single-patch circularly polarized microstrip antenna with dual capacitively coupled feeds, IEEE Trans Antennas Propag 49 (2001), 4144.

7. Nasimuddin, K.P. Esselle, and A.K. Verma, Wideband circularly polarized stacked microstrip antennas, IEEE Antennas Wireless Propag Lett 6 (2007), 21-24.

8. Y.X. Guo, L. Bian, and X.Q. Shi, Broadband circularly polarized annular-ring microstrip antenna, IEEE Trans Antennas Propag 57 (2009), 2474-2477.

9. C.H. Chen, and E.K.N. Yung, Dual-band dual-sense circularly-polarized CPW-fed slot antenna with two spiral slots loaded, IEEE Trans Antennas Propag 57 (2009), 1829-1833.

10. C.J. Wang, and C.H. Chen, CPW-fed stair-shaped slot antennas with circular polarization, IEEE Trans Antennas Propag 57 (2009), 2483-2486.

11. J. Pourahmadazar, C. Ghobadi, J. Nourinia, N. Felegari, and H. Shirzad, Broadband CPW-fed circularly polarized square slot antenna with inverted-L strips for UWB applications, IEEE Antennas Wireless Propag Lett 10 (2011), 369-372.

12. Y.Y. Chen, Y.C. Jiao, G. Zhao, F. Zhang, Z.L. Liao, and Y. Tian, Dual-band dual-sense circularly polarized slot antenna with a C-shaped grounded strip, IEEE Antennas Wireless Propag Lett 10 (2011), 915-918. 
13. N. Felegari, J. Nourinia, C. Ghobadi, and J. Pourahmadazar, Broadband CPW-fed circularly polarized square slot antenna with three inverted-L-shape grounded strips, IEEE Antennas Wireless Propag Lett 10 (2011), 274-277.

14. J.Y. Sze, C.I.G. Hsu, M. H. Ho, Y.H. Ou, and M.W. Wu, Design of circularly polarized annular-ring slot antennas fed by a double-bent microstrip line, IEEE Trans Antennas Propag 55 (2007), 3134-3139.

15. A. Rezaeieh and M. Kartal, A new triple band circularly polarized square slot antenna design with crooked and f-shape for wireless applications, Prog Electromagn Res 121 (2011), $1-18$.

16. D.M. Pozar, Microwave Engineering, 4th ed., Wiley.

17. J.Y. Sze, K.L. Wong, and C.C. Huang, Coplanar waveguidefed square slot antenna for broadband circularly polarised radiation, IEEE Trans Antennas Propag 51 (2003), 21412144.
18. J.-Y. Sze and Y.-H. Ou, Compact CPW-fed square aperture CP antenna for GPS and INMARSAT applications, Microwave Opt Technol Lett 49 (2007), 427-430.

19. C.C. Chou, K.H. Lin, and H.L. Su, Broadband circularly polarized cross-patch-loaded square slot antenna, Electron Lett 43 (2007), 485-486.

20. J.-Y. Sze, J.-C. Wang, and C.-C. Chang, Axial-ratio bandwidth enhancement of asymmetric-CPW-fed circularly-polarised square slot antenna, Electron Lett 44 (2008), 1048-1049.

21. J.-Y. Sze and C.-C. Chang, Circularly polarized square slot antenna with a pair of Inverted-L grounded strips, IEEE Antennas Wireless Propag Lett 7 (2008), 149-151.

22. S. Fu, S. Fang, Z. Wang, and X. Li, Broadband circularly polarized slot antenna array fed by asymmetric CPW for Lband applications, IEEE AWPL Lett 8 (2009), 1014-1015.

23. S. Gao, Q. Yi, A. Sambell, Low-cost broadband circularly polarized printed antennas and array, IEEE Antennas Propag Mag 49 (2007), 57-64.

\section{BIOGRAPHIES}

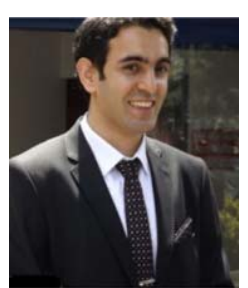

Saeid Karamzadeh, received his MS degree in 2013 and he is Ph.D. candidate in Department of Communication Systems, Satellite Communication \& Remote Sensing program at Istanbul Technical University now. Simultaneously, he is an instructor in the Istanbul Aydin University, Department of Electric and Electronics Engineering. His research interests include remote sensing, radar, signal processing, microwave, and Antenna design.

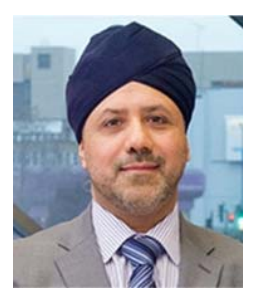

Professor Bal Virdee, graduated with a B.Sc. (Eng) Honours in Communication Engineering and M.Phil. from Leeds University, UK. He obtained his Ph.D. from University of North London, UK. He was worked as an academic at Open University and Leeds University. Prior to this he was an R \& D Electronic Engineer in the Future Products Dept. at Filtronic Components Ltd., Shipley, West Yorkshire, and at PYE TVT (Philips) in Cambridge. He's has held numerous duties and responsibilities at the university, i.e.: Health \& Safety Officer, Postgraduate Tutor, Examination's Officer, Admission's Tutor, Short Course Organiser, Course Leader for B.Sc. Communications Systems and B.Sc. Electronics. Currently, he is Course Leader for M.Sc./M.Eng. Satellite Communications. In 2010 he became an Academic Leader (UG Recruitment). He is a member of ethical committee, member of faculty's research committee, \& research degrees committee.

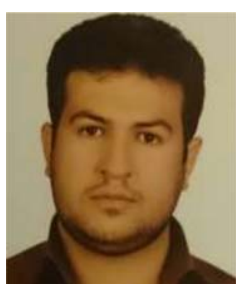

Vahid rafii, was born in Urmia, Iran, in Jan 1986. He received the B.S. degree in Electrical and Telecommunication Engineering from the Urmia Azad University, in 2010 and M.Sc. degree in Electrical and Telecommunication Engineering from Urmia University, Urmia, Iran, in 2013. $\mathrm{He}$ is currently working in northwest antenna and microwave Research Laboratory, Urmia, Iran. He is a member of Iranian Society of Electrical Engineers and young researcher club of Urmia Azad University. He is the author or coauthor of several refereed journal articles and conference papers. His research interests include array and phased array antenna and feed network, beam shaping and beam forming antenna, metamaterial and microwave component, circular polarization antennas, MIMO antennas, mobile phone and wireless local-area network antennas, and their antenna applications.

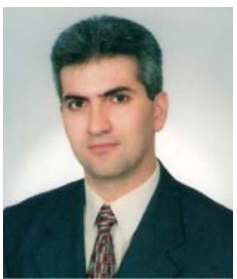

Mesut Kartal, received his MS degree in 1993 and Ph.D. degree in 2000. Currently, he is an associate professor in the Istanbul Technical University, Department of Electronics and Communication Engineering. His research interests include remote sensing, inverse problems, $\mathrm{RF}$ and microwave design engineering, as well as modelling, design, simulations and analysis, and $\mathrm{CAD}$ techniques in high frequency region. 